\title{
Implementation of a System of Improvements in the Management of Changes in Healthcare Facilities - Barrier Analysis
}

\author{
Joanna Jasińska ${ }^{1,2 *}$ \\ ${ }^{1}$ University of Social, Computer \& Medicine Science, Poland \\ ${ }^{2}$ Warsaw Medical University named Tadeusz Kozluk, Vice-Rector for Education and Development, Poland \\ *Corresponding author: Joanna Jasińska, University of Social, Computer \& Medicine Science, Poland; \\ Warsaw Medical University named Tadeusz Kozluk, Vice-Rector for Education and Development, Poland
}

\section{ARTICLE INFO}

Received: 蔧 May 12, 2020

Published: 幽 June 04, 2020

Citation: Joanna Jasińska. Implementation of a System of Improvements in the Management of Changes in Healthcare Facilities - Barrier Analysis. Biomed J Sci \& Tech Res 28(1)-2020. BJSTR. MS.ID.004599.
ABSTRACT

The aim of the scientific article is to identify factors and barriers in the system of supporting change management in healthcare organizations. Based on the results of research conducted in April 2019, the research method is surveys and interviews with healthcare professionals, it was possible to identify the most serious deficiencies in implementing changes. Research has shown a number of barriers that block the innovative activity of employees and managers. The article also presents the manager's activitiesof the analyzed organizations, which aims to mobilize staff to achieve a higher level of functioning of the healthcare facility.

Keywords: Change Management; Continuous Improvement; Pro-Innovative Attitudes

\section{Introduction}

In the current economic situation, healthcare facilities pay special attention to the environment and its signals. They are forced to constantly learn and systematically and quickly act to meet the challenges of public health [1]. Overestimating the resources of health care organizations is a new challenge for organizations that increasingly recognize the need to seek new solutions. In the era of the growing importance of challenges facing public health, people, their knowledge and skills are particularly important. Using and creating new organizational solutions to meet the challenges are a source of competitive advantage. Just Innovations occupy a special place among the success factors. Innovative activities affect the development of healthcare organizations, putting them competitive on the domestic and global market. Creating and implementing innovations is a condition of functioning and development in conditions of increasing health problems [2]. Organizational changes have become a mandatory concept in the strategy for developing healthcare organizations.

Change is highly dependent on potential: intellectual capabilities, organizational and financial necessary for their creation and implementation.The purpose of the publication is to present actions to stimulate changes in the analyzed hospital and barriers to their introduction. These activities appeared in connection with the change in the position of manager. This position was embraced by a person full of energy and ideas for change, who set the goal of activating the medical staff and obtaining higher rates of reporting improvements, deeply and personally engaging in this process.The research was carried out, conducted in 2019 using a questionnaire and interviews with employees, it was possible to determine the most severe shortcomings of the operating system of the hospital.

\section{Factors Supporting Change}

Researchers on change management will focus on analyzing the factors that influence change in organizations [3-5], pointing to factors such as expenditure on R\&D, hospital size, form of ownership, number of employees. Traditionally, for the determinants of activityfactors such as system changes are also recognized health protection, access to information, education, knowledge resources, legal, political and economic regulations, tradition and many others. The development of changes also depends on "soft" 
factors, i.e. human capital. What's more, the role of the latter factors increases significantly in the age of the knowledge-based economy, in which the focus on building enterprise value has been directed at the intangible sources of creating enterprise value, from human capital as the main component. Therefore, an increasing group of researchers is focusing on human aspects of stimulating change, also highlighting the importance strategies, practices and procedures in their creation [6-8]. An important role in this process is played by the personnel function, commitment of leaders, flexible structures enabling quick redirection of time to innovative activities.

Supporting innovation based on personal practices may include the following activities[9]:

a) Communicating the value of change (vision) understanding the value of change, knowledge about how to submit ideas, familiarizing with examples of actions to change,

b) Care for ensuring free access to knowledge, developing and supporting standards and structures aimed at sharing knowledge with others,

c) Innovative leadership - supporting change by managers, open communication of change expectations, management style developing independence, sense of responsibility,

d) Motivating change - rewarding innovation, a system that promotes activities, selection of prizes expected by employees,

e) Building an organizational culture supporting change accepting risk, values conducive to change and strengthening attitudes to change, conviction that new ideas are accepted, that the company expects and supports change, clearly articulating expectations towards employees regarding attitudes and behaviors - initiatives, creativity flexibility,

f) Training and development policy for managing changes formulating training goals as support tools,

g) Changes, analysis of training needs, a wide range of development opportunities,

h) Change in the organization of work - flexibility in redirecting resources in connection with the implementation of changes, no excessive workload, which allows you to develop your own ideas,

i) Teamwork - supporting teamwork, solving problems based on inter-departmental teams, mutual assistance in solving problems,

j) Employee selection - taking into account the knowledge and skills criterion in the selection process.

Many authors [10] indicates a close relationship between practice and Continuous Improvement (CI) systems in the aspect of creating attitudes, behaviors focused on introducing improvements. They also emphasize that systems of this type, such as kaizen, decide about a lasting advantage in creating and implementing change management. Research conducted by these authors indicates that personnel practices exert a significant impact on employees' activity in the area of continuous improvement and organization results, indicating, inter alia, the importance of such aspects as development and learning orientation, explaining errors by searching for reasons, and not blaming employees , commitment, and that they feel that they are process owners.Creating an appropriate climate for change is indispensable for the emergence of innovation, which can be defined as a specific combination of factors including beliefs, values, norms and artifacts regarding health care organization, communication style and establishing relationships between stakeholders, the current leadership model, and motivating system. Change management is fostered by openness, freedom of action, and support for creative ideas, cooperation, knowledge sharing, openness to changes. A climate of trust, risk tolerance and not blaming mistakes, which are part of the process of searching for new solutions, are also necessary $[9,11]$.

\section{Difficulties and Barriers to Introducing Changes}

New ventures can bring great results or fail. When making changes, mistakes are often made that cause the process to fail, such as insufficient communication of the need for change, lack of strong and committed leaders, too few actions to engage employees, and even such absurd reasons as the lack of consistency of top management.This situation is illustrated by the case of actions in one of the hospitals in Poland. "The main purpose of the changes in June 2017 was to change the way changes are implemented and how they are communicated, and overall communication improvement. The effect of this assumed goal was a competition entitled: My Patient, who was directed to all medical workers. Employees submitted many ideas, but they were not rated well by the Board, because they were not professionally prepared in the form of projects. As a result, no winner was selected, and employees felt "cheated" because the ideas were thrown in the trash. From that moment the competition was not repeated [...] ".

The change gives employees fears, resistance, a sense of uncertainty, raises threats that are the basis of substantive and emotional conflicts [12]. Resistance is widespread and unavoidable. It appears primarily when changes are introduced without the participation of the persons they concern. Limit resistance may consist of influencing its causes or supporting attitudes conducive to change. These include communication aimed at education and reducing uncertainty, learning and understanding the causes resistance and giving support, engaging employees in work, consulting and taking their opinions into account.It is also worth considering that in every social system, which is the organization of healthcare, there will be different attitudes towards change. Identifying the so-called change agents and opponents. Opponents they consider the change to be a threat to their benefits in the workplace. Resistance to change can be passive (no involvement in the change process) or active (direct opposition, diversion). 
Change agents are people who see problems and are able to convince the group to fight them. R. Luecke [13] points out that:

1) Change agents are (not necessarily formal) leaders thanks to their own ideas,

2) They can "think differently" and thus may be disliked by management

3) Often have extraordinary experience, so they can see the world through a different lens.

B. Spector [14] indicates that the leverage that gives you the chance to achieve your progress is employee involvement. Schaufeli, et al. [15] note that commitment is a positive, work-related state of mind that is characterized by high energy levels at work, passion, dedication and full concentration on work, sometimes manifesting in reluctance to break away from it. It is accompanied by positive emotions, such as: a sense of pride and significance, enthusiasm, inspiration and challenges related to work. An engaged employee takes into account the broad business context, focusing together with colleagues on improving results to ensure the benefits of the organization.Commitment is also manifested by identification with the entrusted tasks, goals and values of the organization.

\section{Research Methodology}

The aim of the study was to identify factors that would motivate hospital staff to report improvements and increase their commitment to work. To this end, it was also necessary to identify barriers to such behavior in the organization. Conducted research coincided with the conducted hospital changes that aimed to increase activity and employee involvement, with particular emphasis on medical workers. The selection criterion was therefore purposeful. The research was conducted in the third quarter of 2019 using the survey method and partially structured interview. The survey questionnaire used for the research was created as part of the grant research conducted by the author. 106 respondents participated in this part of the survey ( $56 \%$ women and $44 \%$ men. $50 \%$ of respondents medical professionals, $26 \%$ - specialists, $5 \%$ - managers, 19\% - administrative employees. The research was supplemented with a series of interviews with specialist doctors (11 people) and nurses (12 people) - mainly ward nurses. In interviews it took participation of 5 women and 6 men.The interviews were recorded with the consent of the participants. In the further part of the research, the interviews were transcribed as well as data analysis and conclusions were drawn.

\section{The Result of Research}

\section{Results Obtained in Quantitative Research}

Based on the results of the research, it can be assumed that the most serious barriers in the audited entity are deficiencies in terms of organizational values, such as:

a) Fear of a lack of acceptance from colleagues in connection with activity towards, proposed changes (most likely due to experiencing unacceptance in the team),

b) Belief that risk is not accepted,

c) Overwhelming current obligations preventing innovative activities for changes (no organization of work enabling partial exclusion of an innovator for changes from current,

d) Actions and redirecting his activity to work on change),

e) Focus on the current situation of the hospital instead of future-oriented activities.

An important activity in the examined entity would be primarily concentration on knowledge management - increasing access to knowledge and stimulating attitudes aimed at sharing the knowledge necessary for creating change.The study also reveals deficiencies in the system of motivating change. Awards preferred by employees for accepting changes are cash prizes, promotion, participation in the decision-making process, the opportunity to participate in elite training.

\section{Results Obtained Based on Interviews with Medical Workers}

The study identifies seven barriers to changes (kaizens) by medical staff:

Restrictions Resulting from Employee Beliefs: Employees are not sure of the value of their ideas $(n=9)$. They think that these are small things that improve work, have no value for the organization. They often improve their work and use this improvement, but they do not perceive this solution something that could be introduced on a larger scale: "we are not sure. We can ask the man who made this it occupies. Clear evaluation criteria could be useful. "In addition, employees emphasize that it is much easier to make improvements for themselves, even sharing the proposed change, than to fill in the laborious documents necessary for formal notification of a change: "I am very pleased with the facilities I have introduced. I have more time; I can do the rest of the job more properly. This makes work easier. Everyone watches over their norms".They emphasize $(n=4)$ that some of the improvements concern the style of work and do not have to answer everyone, fearing that one of the colleagues may be forced to change the way they work as a result of submitting their idea.

Failure to Notice Benefits for Themselves, or Even Fear of an Increased Number of Duties:Several employees claim that they initially submitted ideas, but many of them withdrew because it is labor-intensive and the salary for ideas is small. In addition, there is a high probability that reporting the improvement will result in increased obligations. It happened that the employee who reported the improvement, he became the object of retaliation of his colleagues, including "why should we do such harm, we have introduced improvements and we have increased the amount of work." Employees emphasize that "ideas are implemented, but they do not work on the person who invented them". 
Sense of Lack of Participation in the Process of Implementing Changes: Respondents indicate that they do not participate in the implementation of their idea. The management explains this by the fact that individual employees do not have the authority to work in specialized departments, therefore further work on the idea can only deal with those who have such permissions. This factor seems so demotivating that it is worth considering limiting its impact on employees' attitudes by creating the possibility of feeling a greater impact on the implementation process.

Insufficient Level of Training in Proposing Changes: This factor is related to the first factor, i.e. perceived uncertainty about the value of ideas, which results from a lack of information and training, "we don't know what they expect, we don't know the criteria." Employees declare $(n=10)$ that the trainings take place too seldom (once a year or less often, in too large groups and last too short (20 minutes). "People are uninformed when it comes to about kaizeny. We come to the hall, the training lasts 20 minutes. " Different study participant indicates "we find out strange things once a year for half an hour." Employees also emphasize $(n=5)$ that it is demotivating that they do not know what the kaizens assessment process looks like. Representatives of medical workers are not involved in this process: "I don't know what's going on with these ideas. Hearing after this is lost. We don't know the way of implementation.

Lack of Time to Implement Your Own Ideas: Another barrier pointed out by employees is the lack of time and therefore the inability to devote it to refine their ideas $(\mathrm{n}=11)$ : "I have to do my job, I have a tight time, time limits. I don't have time for my ideas. “ Another person indicated that he was assessed for doing a specific job, not reporting "Kaizens", "I don't have time to write kaizens. I have some ideas in my head. "It is worth noting that the hospital prides itself on not exerting pressure on employees and does not "force" them to report "Kaizens" as is the case in other hospitals, preferring a positive, incentive-based approach

Sense of Lack of Justice and Ill-Treatment: A sense of justice and the feeling of support of the organization are also very important for building engagement in the work. This seems to be missing in the audited entity. Employees indicate that the system for assessing the value of improvements is underdeveloped $(n=4)$. Below is a statement about this problem. "I know of cases where kaizen didn't work, and someone took the money. It is not fair to me. Maybe it should be checking if it works. If he works, he should be paid extra. Remuneration for the idea and remuneration for working. Two salaries. If someone does not work, he will not get the second salary. Or is this kaizen bothering you? They should do it check".In addition, there are unfair situations that "ideas have been appropriated by the mountain." These types of actions point to serious irregularities. If employees do not perceive the system as fair and transparent, they cannot be counted on to intensify their activity. Another issue is the lack of understanding of employees' needs and problems $(n=5)$.
Lack of Motivation Resulting from the Wrong System of Remuneration for Ideas: Employees agreed that remuneration for "kaizen" is not sufficient. The remuneration does not therefore correspond to the contribution work. Most of the respondents declared that in addition to increasing the remuneration for the implemented ideas, they would also expect greater development opportunities $(n=10)$.Some also pointed out the benefits for the company resulting from the intensification of training processes: "I know what training I would need in my position. Then I could be creative, I would have wider knowledge. I could report improvements. Employees also notice gaps in human capital management. This is illustrated, for example, by the treatment of temporary employees $(n=4)$.

Statement by the Change Management Coordinator: His duties include taking actions to increase the number of reported improvements. It reminds, proposes and draws attention to possibilities. In addition, he is the deputy director of the hospital for changes. The coordinator pointed out a number of difficulties in the process of overcoming negative attitudes towards implemented changes. He pointed out that employees do not understand the benefits of the process and misinterpret the results of assessing the implemented changes. Therefore, the uncertainty of employees regarding the quality of the idea is also a barrier in reporting improvements. Talking to employees overcomes this uncertainty.

\section{Assessment of Changes due to the Way they are Pre- pared}

Theimportance of the change preparation stage is emphasized in all publications on change management. Referring to the principles of efficient operation, it can be said that the stage of preparing changes creates a favorable practical basis for implementing changes. Characterizing this stage in the change management procedure, one can mention the slogan of T. Kotarbiński good work. He wrote that the password is „,... addressed primarily not only to technical devices, but to all entities using them. It demands a brave attitude and efficient organization of the work of both individuals and teams: that it should be done diligently and vigorously, that it should be acted on, that earlier work would be a good preparation of later work, that there would be neither downtime nor meshing, that efforts would not go on miserable but on the contrary, they merged together as effectively as possible " [16].

The majority of surveys of participants in changes in healthcare organizations show that the changes have not been properly prepared. The respondents' opinions on this subject are presented in Figure 1. The negative assessment regarding the preparation of changes was related to organizational, economic, legal and social preparation. Equally negative, considering the number of responses indicating that changes are not prepared for implementation, are the assessment of the changes in terms of substance. $55.00 \%$ of nurses, $66.66 \%$ of doctors, $75.75 \%$ of administration employees and $66.60 \%$ of management staff emphasize the fact that the 
substantive changes are not prepared. The following list cited once again clearly shows the scale of irregularities committed in the process of preparing changes for implementation:

a) The changes were not prepared organizationally - $72.24 \%$,

b) The changes were not financially prepared $-92.90 \%$, c) The changes have legal "shortcomings" - 70.13\%,

d) The changes contain social shortcomings - $85,90 \%$,

e) The changes were not prepared in terms of content above $55.00 \%$,

f) The changes are chaotic $-62.50 \%$ (Figures $1 \& 2$ ).

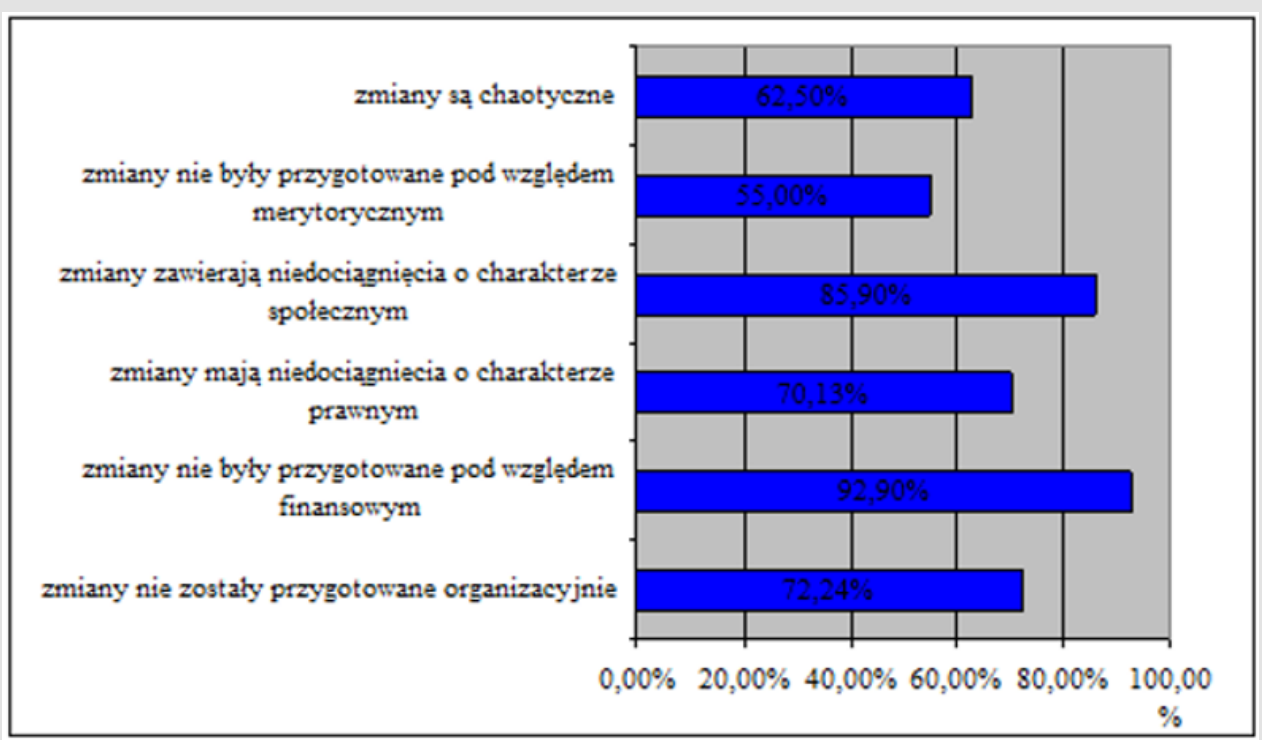

Figure 1: Opinions on the preparation of changes.

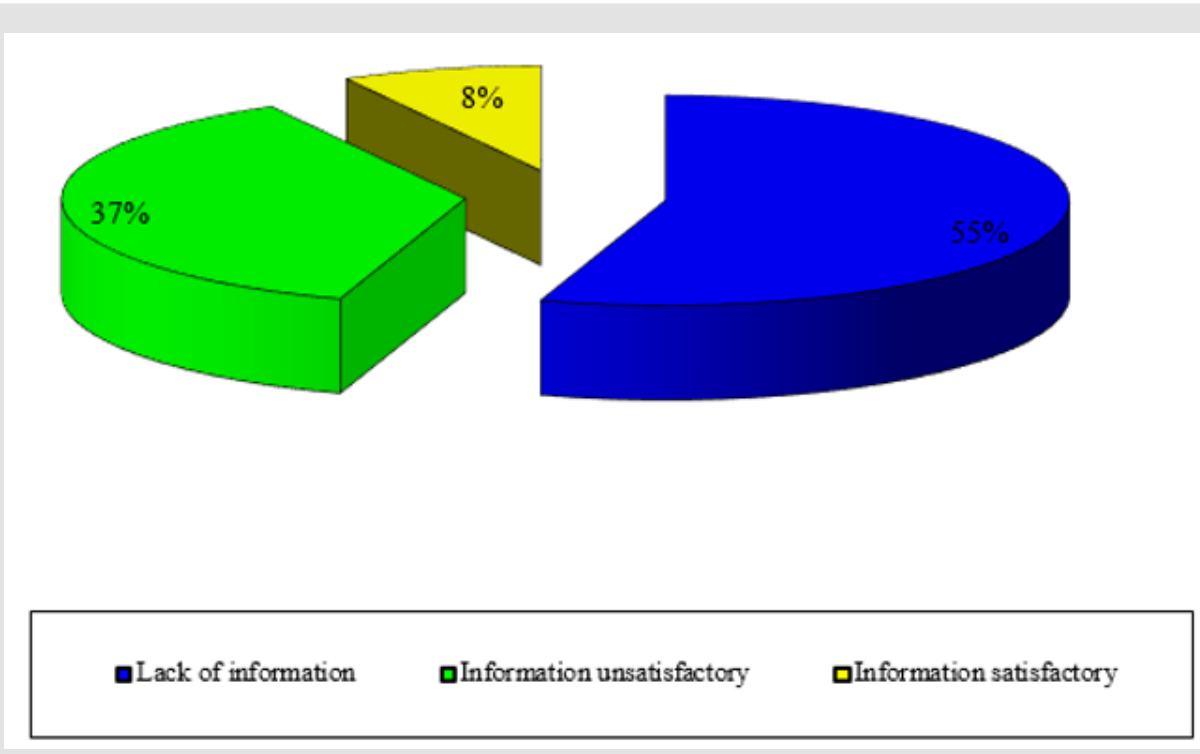

Figure 2: The problems of informative preparation of changes were treated separately.

As emphasized by the respondents, the change that is the vision of the new organization should be presented to all its participants. The more reliable the information, the more efficient the introduction of changes. Information may, for example, be "encouraging", opinion-forming, or controlled, referring to rational or emotional arguments. Each of these types of information is relevant to the change management process. Lack of information or unclear or contradictory information disrupts communication and makes changes difficult.The conducted research shows that changes in healthcare organizations were not prepared in terms of information. $55 \%$ of respondents indicate that there was no information about changes at all 37\%, that the amount of information was insufficient. This means that $92 \%$ of people indicate irregularities in the information preparation of changes. Also, the scale of participation in preparing changes is small (Figure 3). 


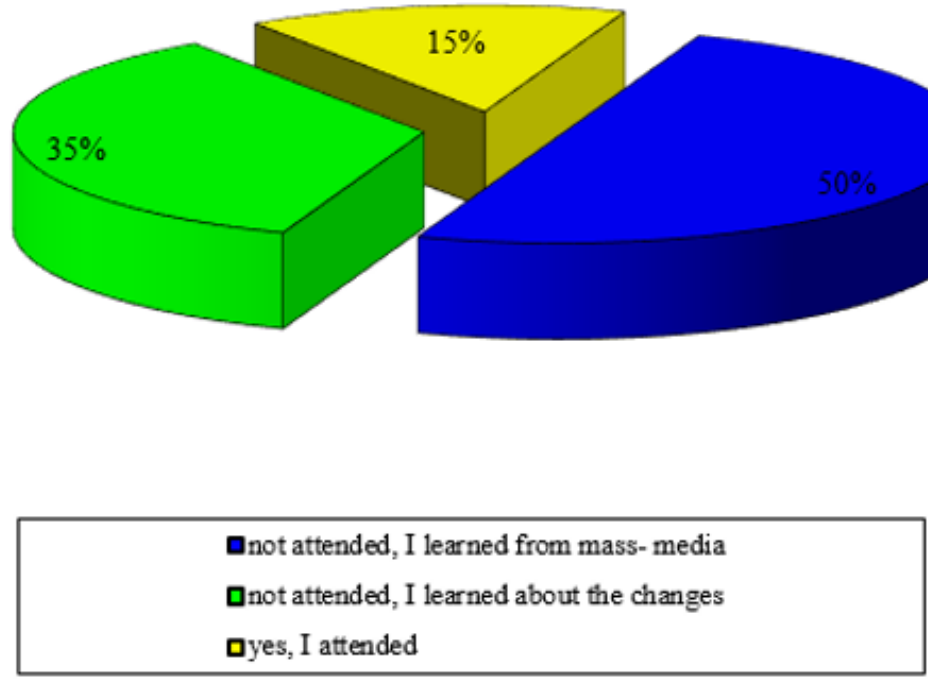

Figure 3: Participation in the preparation of the draft changes.

$85 \%$ of respondents did not participate in the preparation of the draft changes. In connection with irregularities in the information area, this means that the changes have not been subject to consultation with their participants. Particularly critical is the fact that $50 \%$ of respondents learned about changes in non-professional situations.Subjective factors that to some extent differentiate the examined population in terms of informing about changes and participating in their planning are seniority and education of the respondents. Persons with seniority over 30 years of work participated much more often in the preparation of the draft changes. In addition, respondents with more than 30 years of service have been satisfactorily informed of the changes. Also, respondents with higher education feel much more often informed about planned changes than people with secondary education, especially vocational.It is also worth adding that people who participated in the preparation of the draft change consider themselves better informed. In addition, such persons positively assess the changes introduced and their assessment of the preparation of changes in organizational and social terms is positive[17].

\section{Opinions on Changes After Introducing Them}

The functioning of the changes after their introduction, otherwise known as their "freezing" is also a stage requiring special diligence and regularity in observing its course. It should be remembered that the process of changes in the examined health care organizations was initiated in order to improve their economic and organizational condition. Opinions about these changes turned out to be critical.

\section{Perception of Depth of Changes}

Research results indicate that the scope of implemented changes in the organization in the perception of their participants turned out to be diverse. Also, their depth was not assessed equally. For $34 \%$ of respondents, the changes carried out so far are of little importance, slightly less - 30\% of respondents believe that the changes were only apparent, not insignificant. Only $27 \%$ of respondents assess changes as appropriate. In turn, only $9 \%$ of respondents assess that the changes were profound (Figure 4).

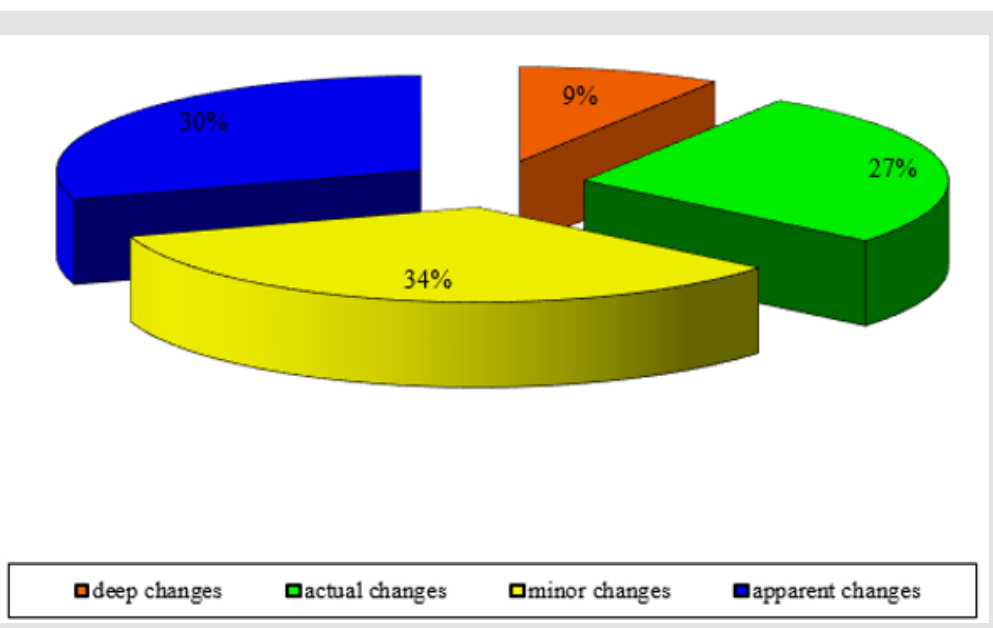

Figure 4: Respondents according to the assessment of depth of changes. 
The above data shows that $64 \%$ of respondents critically assess changes, but it is puzzling that $30 \%$ of them believe that the changes are only apparent and are not relevant to the functioning of the organization.The results of assessing the depth of changes depending on the position in the organization of health care are interesting. Most of the employees of all analyzed professional groups assess the changes as insignificant: $65.5 \%$ of administrative employees, $44.7 \%$ of nurses, $37 \%$ of doctors and $41.6 \%$ of management.The analyzed data shows that for $74 \%$ of doctors, the changes made are not significant for the functioning of healthcare organizations. Similarly, for $89.6 \%$ of administration employees.
In turn, in the management's assessment, an identical percentage distribution of responses appears for the statement that the changes are apparent (27.7\%) and that they are deep (27.7\%) Table 1. Administrative staff are the most critical towards changes. People from this occupational flu more often than representatives of other groups believe that the changes are not significant or apparent (89.6\% of responses). Nurses are also critical of the changes. However, doctors more often emphasize that the changes are apparent $(37.0 \%)$. None of the people in this professional category assessed the changes as appropriate (Table 1).

Table 1: Assessment of the depth of changes depending on the position held $(\mathrm{N}=177)$.

\begin{tabular}{|c|c|c|c|c|c|c|c|c|}
\hline \multirow{2}{*}{ Position } & \multicolumn{2}{|c|}{ Minor Changes } & \multicolumn{2}{|c|}{ Apparent Changes } & \multicolumn{2}{|c|}{ Deep Changes } & \multicolumn{2}{|c|}{ Actual Changes } \\
\hline & Liczba & $\%$ & Liczba & $\%$ & Liczba & $\%$ & Liczba & $\%$ \\
\hline Administration & 19 & 65,50 & 7 & 24,10 & 2 & 6,80 & 1 & 3,40 \\
\hline Nurses / Midwives & 38 & 44,70 & 17 & 20,00 & 21 & 24,70 & 9 & 10,50 \\
\hline Doctors & 10 & 37,00 & 10 & 37,00 & 7 & 25,90 & 0 & 0,0 \\
\hline Management & 15 & 41,60 & 10 & 27,70 & 10 & 27,70 & 1 & 2,70 \\
\hline
\end{tabular}

\section{Perception of the Subject Scope of Changes}

Literature representing the consideration of change management in the current of their interests has included various suggestions on the typology of changes. We find in it a rich variety of applied classification criteria. We meet such criteria as:

a) Related to the subject of the changes,

b) Related to the global context of change,

c) Related to specific subsystems or functions of the organization.

Typologies are also distinguished based on such criteria, which were taken into account in the previously presented issues of perception of depth of change. At this point of consideration, the material scope of the changes was assessed, assuming that this assessment will reveal a key area for focusing the perception of focusing changes in healthcare organizations.

The results of the conducted research indicate that the following changes took place in the social assessment of the changes made (chart 29):
a) Personal - 47\%,
b) Organizational - $22 \%$,
c) Management changes - $11 \%$,
d) Technical - 8\%,

e) Privatization - $12 \%$

In the hierarchy of answers, the first and second place are occupied by personnel and organizational changes. As many as $69 \%$ of respondents see these two types of changes. The remaining respondents divide the changes into changes in management, privatization and technical.

The answers of the respondents employed in a large healthcare organization are similar in terms of perception of the dominant scope of personnel changes of employees of this organization (56.4\%). Also, employees of smaller healthcare organizations express a similar opinion - $65 \%$ of respondents.Similarly, according to nurses, the changes carried out so far mainly consisted of personnel changes. $51.48 \%$ of people from this group answered yes to the question asked in this matter. Also, in other professional groups this type of changes obtained a dominant number of responses.The analysis of opinions on implemented changes, depending on the age of the respondents, does not change the hierarchy of opinions on the changes made. Respondents agree that the changes carried out so far consisted primarily of personnel changes. Opinion on this issue:

a) $55.90 \%$ of people up to 34 years old,

b) $75.00 \%$ of people between 35 and 44 years old,

c) $61.20 \%$ of people between 45 and 64 years of age(Table 2). 
Table 2: Opinions on personnel changes depending on the age of the respondents $(\mathrm{N}=198)$.

\begin{tabular}{|c|c|c|c|c|}
\hline \multirow{2}{*}{ Age of Respondents } & \multicolumn{2}{|c|}{ Yes } & \multicolumn{2}{c|}{ No } \\
\cline { 2 - 5 } & Liczba & L & 37 & 44,00 \\
\hline Down 34 years & 47 & 55,90 & 13 & 25,00 \\
\hline From 35 - 44 years & 39 & 75,00 & 24 & 38,70 \\
\hline From 45 - 64 years & 38 & 61,20 & \\
\hline
\end{tabular}

\section{Assessment of People Introducing Changes}

Opinions on those introducing changes are clearly oriented towards negative assessment. Over $40 \%$ of the respondents gave a negative assessment to these people. In contrast, $42 \%$ decided not to speak on this subject.

Only $15 \%$ of respondents indicate confidence in change managers. This is particularly worrying, because it depends on them to a large extent whether the changes will be accepted and whether the participants of the change will want to be actively involved in their implementation.Lack of trust in people who introduce changes and "escape" from the answer can be seen also in the case of analyzing the opinions of respondents in terms of seniority in healthcare organization (Table 3). The analysis shows a lack of trust, most often people with 11 to 20 years of experience express this opinion and over 30 years of service. In addition, people with more than 30 years of experience ignore the possibility of answering: small and high confidence in those introducing changes. It should also be emphasized that in the opinion of more than half of the respondents, change managers should have extensive knowledge in this area (56\%). Although $44 \%$ of respondents do not share this view.The presented research results reflect the situation in the field of change management in the examined health care organizations. They indicate that irregularities have occurred in the change process [18,19].

Table 3: Respondents' opinions on trust in people introducing changes - opinions depending on the seniority $(\mathrm{N}=199)$.

\begin{tabular}{|c|c|c|c|c|c|c|c|c|}
\hline \multirow{2}{*}{ Rating } & \multicolumn{2}{|c|}{ Lack of Trust } & \multicolumn{2}{c|}{ Little Trust } & \multicolumn{2}{c|}{ Big Trust } & \multicolumn{2}{c|}{ I do not Speak } \\
\cline { 2 - 10 } & Number & $\mathbf{\%}$ & Number & $\mathbf{\%}$ & Number & \% & Number & \% \\
\hline Down 10 years & 8 & 19,00 & 2 & 4,70 & 16 & 38,00 & 16 & 38,00 \\
\hline From 11 - 20 years & 25 & 26,00 & 19 & 19,70 & 13 & 13,50 & 39 & 40,00 \\
\hline From 21- 30 years & 11 & 21,00 & 12 & 23,00 & 12 & 23,00 & 17 & 32,60 \\
\hline Powyżej 30 years & 2 & 22,20 & 0 & 0,0 & 0 & 0,0 & 7 & 77,70 \\
\hline
\end{tabular}

\section{Conclusion}

"Man, as a unique value, should be the central link in the management process"[2] - this opinion can be found in most management publications. People in healthcare organizations should also be their value and capital. In practice, irregularities observed in this area create a not very favorable picture of reality, contributing to the undermining the credibility of the organization's operation, which may result in their functional crisis.Empirical studies prove that both institutions supervising the functioning of healthcare organizations and participants of these organizations are unable to change them in a way that ensures efficient implementation of changes. First of all, one of the main factors for the success of the change management process, i.e. social acceptance, has failed. Participants of changes primarily feel uninformed (92\%). They also do not take part in shaping the concept of change (85\%). In addition, the respondents assess that the benefits of the change process apply to a smaller extent to the entire organization and to its individual employees.

Disturbances in the change management process (organizational, substantive, economic) were therefore accompanied by insufficient support of the proposed changes by the social system of the organization. It can be assumed that the awareness of the partners participating in the change process is far from the postulated state. It is also worth noting that the participants of changes on the one hand see a deep economic crisis in the organizations surveyed $(78.78 \%$ of respondents assesses the economic status of their organizations as unstable), while at the same time $70.83 \%$ of people believe that the source of change is primarily external factors (regional policy). This situation means that the directions of changes may differ from the real needs of the organization, placing them in the position of change recipients, not active wizards. At this point it is worth mentioning that $30 \%$ of the respondents consider the changes to be apparent, and only $27 \%$ to be appropriate.The research also confirms that the management responsible for the content of their role for change processes also assesses the changes as minor (41.6\%) and apparent (27.7\%).

Based on the opinions of the surveyed participants in healthcare organizations, it is difficult to determine the strength and quality of the relationship between the causes of changes and the quality of health services provided. It should be emphasized that $91.95 \%$ of people do not see the sources of changes in the increased requirements of healthcare organization beneficiaries. There are also no signals confirming the role of this source and its positive impact on the status of services offered by these organizations. Research results also indicate insufficient management changes, 
which is clearly visible in the assessments of the respondents. This dissonance between undoubtedly the need for changes in management and the lack of their fulfillment may constitute the foundation and source of failures related to change management in healthcare organizations. If this process intensifies, healthcare organizations will remain still despite the changes. This danger seems real.The presented research results also indicate a lack of trust in people introducing changes ( $85 \%$ of respondents). Opinion diagnosis indicates how high a positive place in the hierarchy of changes in the social dimension is for those who make changes.

The social value of change, as can be judged on the basis of research results, occupies a peripheral place for decision-makers. It can be assumed that this situation is a reflection of the orientation of changes on achieving instrumental values. It may also indicate huge gaps in the substantive preparation of people introducing changes in healthcare organizations. Peripherality of the social value of changes may also result from treating change management processes in healthcare organizations as forced and imposed evil. The complexity of the functioning of healthcare organizations builds the complicated reality of change in this socially important area of services. Nowadays, this is an area where chaotic and hardly predictable events and processes dominate, and external events seem to govern the organization, not the organization of events. The most important problem of changes in healthcare organizations, as shown by the research of change participants, lies in the social system of these organizations. Despite this, one cannot forget that organizational, economic and legal barriers also appear in the process of change. In addition, change cannot be treated as a one-off event, it is because a process in which various elements combine and penetrate into a unique and specific whole, essential for the functioning and development of healthcare organizations.

\section{References}

1. Cieśliński BW (2011) Improving process orientation of enterprises: model of process training platform. Scientific Works of the Wrocław University of Economics. Series: Monographs and Studies 155: 251.

2. Johannessen JA, Olsen B, Lumpkin GT (2001) Innovation as newness: what is new, how new, and new to whom? European Journal of Innovation Management 4(1): 20-31.

ISSN: 2574-1241

DOI: 10.26717/BJSTR.2020.28.004599

Joanna Jasińska. Biomed J Sci \& Tech Res

This work is licensed under Creative Commons Attribution 4.0 License

Submission Link: https://biomedres.us/submit-manuscript.php
3. Kleinknecht A, Mohnen P (2002) Innovation and Firm Performance: Econometric Explorations of Survey Data. Palgrave, Basingstoke pp. 327.

4. Zakrzewska Bielawska A (2015) The strategic dilemmas of innovative enterprises: proposals for high-technology sectors. R\&D Management 42(4): 303-314.

5. Zakrzewska Bielawska A (2015) High Technology Company - Concept, Nature, Characteristics. Recent Advances in Management, Marketing, Finances.

6. Nijhof A, Krabbendam K, Looise JC (2015) Innovation through exemptions: building upon the existing creativity of employees. Technovation 22(11): 675-683.

7. Lau CM, Ngo HY (2004) The HR system, organizational culture, and product innovation. International Business Review 13(6): 685-703.

8. Mazzanti M, Pini P, Tortia E (2006) Organizational innovations, human resources and firm performance: The Emilia-Romagna food sector. The Journal of Socio-Economics 35(1): 123-141.

9. Krot K, Lewicka D (2012) The importance of trust in manager-employee relationships. International Journal of Electronic Business Management 10(3): 224-233.

10. Jørgensen F, Timenes Laugen B, Boer H (2007) Human resource management for continuous improvement. Creativity and Innovation Management 16(4): 363-375.

11. Krot K, Lewicka D (2011) Human side of innovation-individual and organisational environment-related aspects: The case of IBM. International Journal of Innovation and Learning 9(4): 352-371.

12. Penc J (2008) Decisions and changes in the organization: in search of effective ways of acting. Warsaw: Difin.

13. Luecke R (2016) Creativity and Innovation Management, Harvard Business School Publishing Corporation, Warsaw.

14. Spector B (2018) Introducing a change in the organization. PWN Scientific Publisher.

15. Schaufeli WB, Taris TW, Bakker AB (2006) Dr Jekyll and Mr Hyde: on the differences between work engagement and workaholism. RJ Burke (Eds.)., New horizons in management. Research companion to working time and work addiction pp.193-217.

16. Kotarbiński T (1969) Traktat o dobrej robocie. Ossolineum, Wrocław.

17. Kotter JP (1995) Leading Change: Why Transformation Efforts Fail Harvard Business Review.

18. Storz C (2018) Dynamics in innovation systems: evidence from Japan's game software industry. Research Policy 37(9): 1480-1491.

19. C Aida Bulucea, A Series of Reference Books and Textbooks, Published by WSEAS Press, Penang, Malaysia p. 93-98.

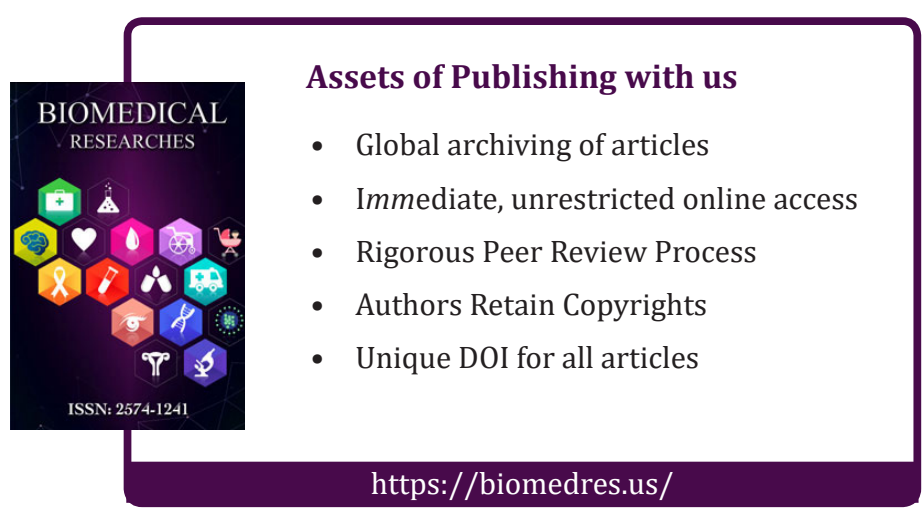

